\title{
A Critical Review of Steroid Immunotherapy in Kidney Transplantation
}

\section{Oluwatoyin Bamgbola*}

Division of Pediatric Nephrology, SUNY DMC, Brooklyn, USA

*Corresponding author: Oluwatoyin Bamgbola, Division Director, Pediatric Nephrology, SUNY DMC, Brooklyn, NY, USA, E-mail: fbamgbola@gmail.com

\begin{abstract}
Steroid immunosuppression has maintained a long-lasting relevance in renal transplantation. In addition to its role in preserving allograft survival, it is often the first line agent in the rescue treatment of acute rejection events. Its major drawbacks include metabolic adverse effects and long-term cardiovascular morbidities. Motivated by the need to avoid growth impairment, pediatric renal transplant community provided a template for steroid minimization strategy. Steroid sparing regimens are often successful in the context of induction therapy with lymphocyte depleting agents. Because most randomized controlled trials are conducted for duration of 1 to 5 years, it is unclear if steroid-based protocol confers a longer renal allograft life span. By avoiding earlyonset rejection, steroid prevents exposure of immunogenic epitopes and therefore reduces the development of late-onset antibodymediated allograft injury. In contrast to the calcineurin inhibitors, steroid promotes allograft tolerance by enhancing preservation of the regulatory $\mathrm{T}$ cells. It suppresses inflammatory response to ischemic reperfusion events as produced by transplant surgery. Its anti-inflammatory effects are most beneficial in patients with high immunologic risk profiles. Finally, future therapeutic approach may embrace careful selection of most suitable drug regimen for an individual by using bio-molecular resources for risk categorization.
\end{abstract}

\section{Introduction}

In the last six decades, we've witnessed a revolutionary success in short- and medium-term survival rates of renal allograft. Greater understanding of transplant immunology has led to an innovative use of immunosuppressive agents (ISA). However, recent data suggest the inadequacy of current ISA (rather than drug-induced toxicity) is the major culprit for late-onset allograft loss [1]. This is reflected by the association of the latter event with de novo development of donor specific antibody. This observation calls for cautious interpretation of data from short-term clinical trials on steroid minimization strategies. Indeed decision on the modality of steroid use must be supported by adequate knowledge of its pharmacology in multiple clinical settings. Given the long history of its use, there are available excellent data sources that are suitable for such inferential deduction. Hence, this article will examine the biological basis of steroid effectiveness, the mechanisms for its common adverse effects and the scientific merit for its combination with other ISA. The goal is to provide readers with theoretical background to enable him / her appreciate the desirability of steroid use [or non-use] in renal transplantation. For an in-depth analysis of the role of other classes of ISA, readers are referred to previous excellent reviews by other authors $[1,2]$.

\section{Steroids: historical context}

Steroid was a pioneering ISA for the first cohort of kidney transplant recipients (KTR) in the early 1960s [3]. Its combination with azathioprine (AZA) produced a very modest one-year graft survival rate, barely reaching 40 to $50 \%$ [3]. Subsequent introduction of calcineurin inhibitors (CNI), mycophenolate mofetil (MMF), rapamycin (RAP) and lymphocyte depleting agents led to one-year graft survival rate in excess of $90 \%[4,5]$. This extra-ordinary feat was, in part, due to the vast improvement in both surgical and organ preservation technologies. However in the last two decades, the steady increase in life span of renal transplant has been driven principally by the attrition rate in the first year. Due to inadequate immunosuppression and/or drug-induced nephrotoxicity, long-term allograft survival has been less satisfactory [4]. Thus rate of deceased donor graft loss in the first year dropped from $20 \%$ in 1989 to $7 \%$ in 2008 , but it remained steadily constant at 5-7\% over the same period for those that survived beyond one year [6].

\section{Steroids Minimization Strategies}

United States registry data showed that more than $25 \%$ of the patients who are discharged from hospital after the transplant surgery have had a successful discontinuation of steroids treatment [6]. Although there is no consensus on the nomenclature for minimization strategies, for simplicity we shall use the following definitions: i) Steroid free: A strict definition of a complete elimination would imply there is no steroid use for induction, maintenance or as a rescue therapy for acute rejection (AR). Such approach will result in over-reliance on lymphocyte depleting antibodies and thereby expose patients to avoidable side effects. For this reason, most patients with $\mathrm{AR}$ are often treated with pulse doses of steroids. ii) Steroid avoidance is defined as discontinuation of glucocorticoids (GC) within 7 days of transplant surgery. Duration of steroid treatment for less than 3 days produces more frequent delayed graft function [7]. iii) Steroid withdrawal: Early withdrawal refers to discontinuation of steroids use between 7 and 14 days. Late withdrawals are achieved at various time points after 14 days of treatment. Up to 3 , 6 and 12 months of GC use have been reported. It is associated with greater risk of graft rejection [8].

\section{Adjunctive Steroid Use during Induction Therapy}

To enhance immunosuppression, renal allograft recipients placed on steroid minimization protocols are often treated with induction 
agents [4-8]. Due to superior efficacy, anti-thymocyte globulin (ATG) is often preferred in high risk patients. Compared with alemtuzumab, it is associated with lower rate of $\mathrm{AR}$, and a longer duration of allograft survival $[9,10]$. Non-depleting monoclonal antibody (basiliximab, an IL-2 receptor agonist) has a wider therapeutic window and is therefore the treatment of choice in low risk recipients [11,12]. Adjunct treatment with methyl prednisolone $(5-10 \mathrm{mg} / \mathrm{kg})$ during surgery may produce crucial non-immunologic benefits [13]. It suppresses the release of pro-inflammatory cytokines (interleukin-6 (IL-6), IL8 , TNF- $\alpha$ ) in response to ischemic reperfusion injury. Furthermore, partly due to the anti-inflammatory effect, peri-transplant steroid use has been associated with a shorter duration of post-surgery hospitalization [13].

\section{Clinical Trials on Steroid Minimization Protocol}

Comparison of studies on steroid sparing regimen is often confounded by variation in induction strategy, steroid doses, drug combination, co-morbidity pattern, and the choice of clinical endpoints $[8,14-16]$. Although similar rate of long-term allograft survival is observed in meta-analysis data, patients treated with steroid sparing protocols often showed higher rate of ARE but a less frequent metabolic side-effect $[8,14-16]$. The first RCT was performed in Canada in the early 1980s. Patients were randomized to receive either CsA only or in a combination with prednisolone. There was a greater need for steroid rescue and a lower rate of graft survival in the (CsA arm) former [15]. Similarly, CsA and mycophenolate sodium were utilized as maintenance agents in FREEDOM trial [16]. Greater proportion (41\%) of the group treated with steroid-free protocol required rescue therapy compared with those $(29 \%)$ on the early-withdrawal regimen [16]. Consequently, standard maintenance immunosuppression comprises of two or more classes of drug. This approach permits the use of minimum effective dose of these agents while curtailing their serious side effects $[4,17]$.

\section{Combination Therapy with Steroids}

Calcineurin inhibitor is widely considered as the most effective ISA used for the prevention of allograft rejection. Attempts to avoid these agents often result in greater rejection episodes and lower graft survival [4]. Hence tacrolimus and MMF with [and without] steroids are the initial drug combination in most patients [17].

Calcineurin inhibitor allows the preservation of essential immune function by producing a selective de-activation of specific lymphocyte function. Its major drawback is a dose-dependent renal toxicity $[4,18]$.Compared with CsA, tacrolimus (TAC) produces a more favorable cardiovascular profile $[18,19]$. In a meta-analysis, ARE was avoided in 12 recipients and graft losses were prevented in 2 out of every 100 patients after 1 year of using TAC instead of CsA [20]. Concurrent steroid use may potentiate the metabolic complications [21]. Although lower doses of CNI may minimize adverse effects in high risk patients, there may be need for larger doses of steroids to prevent rejection episodes [22]. On the other hand, steroid use may attenuate CNI toxicity by decreasing its tubular accumulation via the activation of P-glycoprotein, a multi-drug efflux system [23]. Similarly, proximal tubular expression of (steroid-inducible) cytochrome P450-3A5 enzyme correlated inversely with the histology markers of cyclosporine injury [24] (Table 1).

\section{Sirolimus}

Because of its anti-proliferative effect, there was initial enthusiasm that sirolimus (SRL) use might prolong allograft survival. However, in SYMPHONY trial, treatment with SRL was associated with the highest rate of ARE [25]. In addition, it failed to improve graft survival when used as a late substitute for CNI $[4,25,26]$. Everolimus, a derivative of SRL, has a similar immunosuppressive efficacy in renal transplantation. Both are associated with side effects that include new onset proteinuria, pneumonitis, hepatotoxicity, thrombotic microangiopathy, hyperlipidemia and delayed wound healing $[27,28]$. The last two events may be exacerbated by concurrent use of high dose steroids [4,25-28].

\section{Mycophenolatemofetil}

A RCT of steroid minimization strategy in which there was exclusion of MMF showed a higher rate of ARE and a double-fold increase in the short-term graft losses [29]. Similarly, patients with single nucleotide polymorphism [SNP] for uridine diphosphate glucuronosyl-transferase (UGT2B7), the metabolizing enzyme for MMF, experienced higher rate of ARE [30]. Demonstrating its superior efficacy over AZA, patients placed on MMF had lower events of graft losses [29]. However, such advantage was abrogated in a protocol that combined CNI, steroids and AZA after induction therapy with ATG [31].In addition, AZA may be more cost effective than MMF. Theoretically, steroid combination with either MMF or AZA may attenuate their suppressive effects on the bone marrow. However, unlike steroid up-regulation of Foxp3 (+) regulatory T cells, MMF reduced the functional capacity for post-ischemic tissue repair [32]. Finally, a combined use of TAC and MMF may promote BK virus replication by aggravating functional impairment of cytotoxic CD8 (+) T-cell [33].

\section{Belatacept}

Belatacept, recently approved by United States Food and Drug Administration (FDA), is a CTLA4Ig fusion protein that blocks costimulatory activation of the CD28 receptors on T cells. It produces higher rate of early-onset ARE, greater preservation of 12-month graft function but a similar rate of 5-year survival [34]. Due to a favorable cardiovascular profile, it may be more suitable than CNI for a combined treatment with steroids [35]. Although phase III trial had initially suggested there is a higher incidence of post-transplant lymph proliferative disorder, subsequent meta-analysis of multiple studies disproved this conclusion [34-36].

\section{High Immunologic Risk Patients}

In a given individual, categorization of the risk profiles may determine the appropriate selection of ISA. In majority of the studies, beneficial effects of steroids are most pronounced in high immunologic risk patients [37,38]. These patients are particularly susceptible to late-onset chronic graft rejection. On the other hand, minimization of steroids and CNI may be more suitable for those at higher risk for cardiovascular morbidity [36-38]. A prospective study of early steroid withdrawal showed greater events of acute rejection in African-American recipients of kidneys from poorly matched donors [39]. Similarly, there is a four-fold greater risk of developing recurrent glomerulonephritis in steroid free recipients. Finally, a second episode of rejection is more likely to occur in the absence of GC maintenance after a rescue steroid treatment of ARE [40].

Theoretically, treatment with steroid may also reduce the development of late-onset antibody-mediated graft injury. The latter may be elicited by an inadvertent (prior) exposure to immunogenic epitopes [1,41]. The functional cooperation between the T- and B-lymphocytes may in part explain this phenomenon. In this regard, alloantigen internalized by B-cells is degraded into smaller peptides which are then expressed on the cell surfaces by MHC class II molecules [42]. Consequently, the antigen-presenting B lymphocyte forms an immunological synapse with the cognate receptor of CD4+ T-helper cells. The T-lymphocyte in turn stimulates antibody production from the $\mathrm{B}$ cells while there is a parallel activation of CD8 cytotoxicity. By enhancing apoptosis of both $\mathrm{T}$ - and B- lymphocytes, steroids reduce the opportunity for this immunological interaction [42]. Furthermore, it promotes hypo responsive state by reducing the exposure of allo-antigen to B cells and by inducing a selective preservation of the regulatory T-cells [43].

\section{Steroids Metabolism and Cytochrome P450}

Prednisone is metabolized to the active agent, prednisolone in the liver. Its metabolic clearance depends on both hepatic cytochrome P450 and intestinal P-glycoprotein systems. Drug interaction, old age and ethnicity may account for the random variation in the bio-availability of steroids in transplant recipients [44-51]. Furthermore, due to increased 


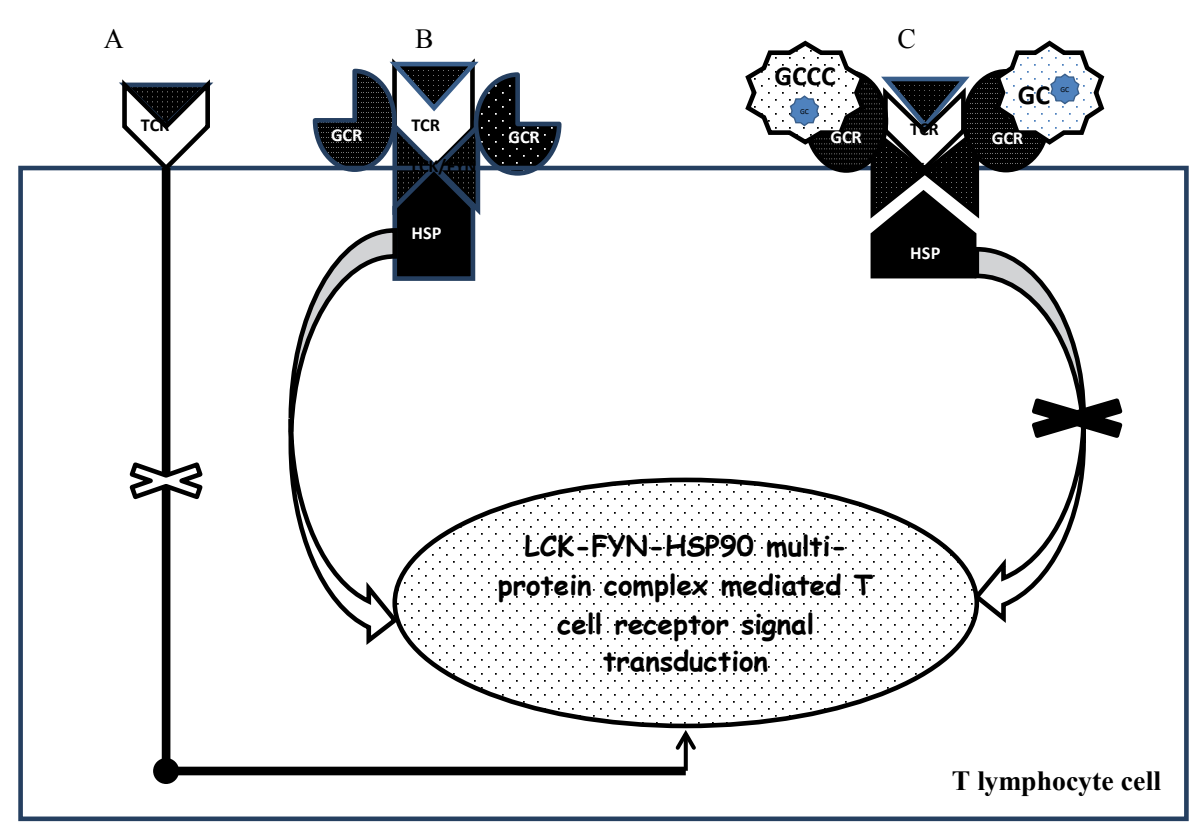

Figure 1: Molecular mechanism for the non-genomic inhibition of T cell receptor signaling system mediated by the GC activation of cell membrane-bound receptors.

(A).Activation of T cell receptor (TCR) on cell membrane is ineffective in the absence of multi-protein complex that includes membrane bound GC receptor (GCR), heat-shock proteinschaperone system (HSP), lymphocyte-specific protein tyrosine kinase (LCK) and FYN oncogene (B). Successful activation of T cell receptor bound to multi-protein complex by a ligand (C). GC ligation of the membrane-bound receptor causes inactivation of the T cell signaling by producingthe dissociation of LCK-FYN-HSP-GCR complex.

metabolic clearance from large fat mass and higher hepatic blood flow, unadjusted dosing of steroids may result in sub-therapeutic exposure in obese patients. For these reasons, the traditional use of one-size-fits-all steroid treatment may contribute to a sub-optimal efficacy.

In the future, in addition to demographic risk categorization, genetic, metabolic and immunologic profiles may identify individuals that are best suited for a class of ISA. Although validation studies are needed, higher expression of RC isoform of CD45 molecule (CD45RC) on the surfaces of CD8 $\mathrm{T}$ cells in pre-transplant patients was predictive of ARE [45]. Similarly, measurement of lymphocyte proliferation in response to (a given amount of) endogenous cortisol identified those who are likely to fail steroid withdrawal [46]. In addition, pre-transplant serum levels of soluble CD30 correlate with the greater incidence of early onset AR events [47]. However, due to the confounding effect of single nucleotide polymorphisms, there are inconsistent findings on the relationship between cytochrome P450 genotype and CNI pharmacokinetics [48]. Finally, a development of auto-antibody to cytochrome P450 may lower the metabolic clearance of susceptible drugs [49]. This scenario is more likely in transplant recipients with auto-immune disorders and should be suspected if there is a sudden [unexplained] decline in CNI trough levels. Further studies are warranted to determine if there is a modulatory role of steroids in this circumstance.

\section{Steroid-Drug Interaction}

Due to utilization of a common metabolic pathway, steroid increases the clearance of both calcineurin inhibitors and sirolimus. To a lesser degree it enhances enzymatic clearance of MMF by activation of uridinediphosphate-glucuronosyltransferase and the multidrug resistance-associated protein 2 [50]. Hence adverse clinical outcome must be monitored anytime there is a change in the drug combination [50,51]. For example, rapid tapering of steroids may increase tacrolimus exposure in fast drug metabolizers (homozygous cytochrome P450 3A5 genotype) while there is slower rate of metabolism in those with obesity and/ or hepatitis C infection [51].

\section{Mechanisms of Glucocorticoid Efficacy}

\section{Non-genomic mechanism}

Cellular activity of steroid is mediated by both genomic and non- genomic mechanisms [52]. The latter is less robust but has a rapid onset of action. It is mediated by membrane bound receptors. Its effect is blocked by mifepristone [a receptor antagonist] but it is not affected by actinomycin $\mathrm{D}$, a transcription inhibitor [53]. Activation of receptors on the surface of T-cell (TCR) is ineffective in the absence of multi-protein complex of membrane-bound GC receptor (GCR), heat-shock proteins (HSP), lymphocyte-specific protein tyrosine kinase (LCK) and FYN oncogene. Glucocorticoid binding of TCR causes dissociation of the cytosolic LCK-FYN-HSP-GCR complex and therefore prevents the activation of signal transduction (Figure $1)$.

On the other hand, binding of glucocorticoid to the receptor stimulates phosphatidylinositol 3-kinase and protein kinase AKT. It activates endothelial nitric oxide synthase (eNOS) and inhibits the release of prostaglandin PGE2 [54,55]. Consequently, there is down-regulation of endothelial adhesion molecules, inhibition of neutrophil migration and prevention of phagocytosis. It minimizes enzymatic tissue injury by a reduction of the neutrophil secretion of elastase and collagenase; and suppresses the development of microvascular thrombosis by its inhibition of plasminogen activator [56]. Glucocorticoid depletes peripheral lymphocytes by promoting its sequestration within the reticulo-endothelial system but produces leucocytosis by systemic release of neutrophils from the bone marrow [57,58]. It inhibits lymphocyte activation and alters its action cytoskeleton by the dephosphorylation of ezrin-radixinmoesin protein $[59,60]$. This causes inhibition of the migration of effector T-cell and therefore reduces its interaction with prevailing allo-antigens [60]. Suppression of ezrin-moesin proteins may also decrease calcium influx which in turn reduces the intracellular signaling for IL-2 synthesis [61].

\section{Genomic mechanism}

Genome-mediated cellular response has a slower onset but produces a more prolific biological activity. It involves translocation of cytosolic GC-bound-receptor into the nucleus where it binds steroid responsive elements (Figure 2). Inhibition of nuclear factor kappa B (NF- $\kappa \mathrm{B})$ repressed transcription of genes for the synthesis of pro-inflammatory mediators including IL-1, interferon-alfa [62], and inducible nitric oxide synthase 


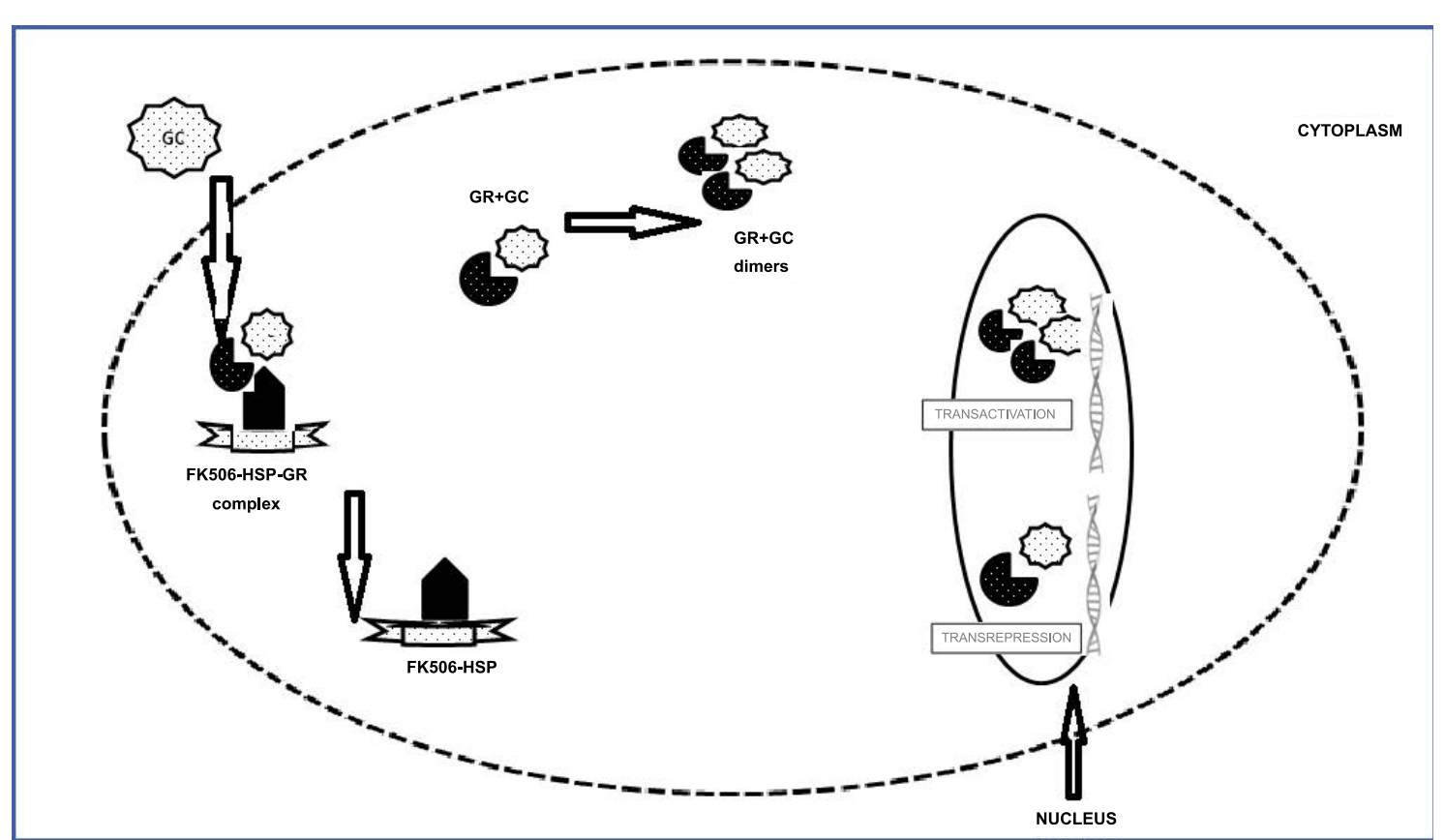

Figure 2: Simplified illustration of the cytosolic glucocorticoid binding system and translocation of the steroid-receptor complexes into the nucleus for the genemediated cellular function.

Extracellular glucocorticoid (GC) dissociates from steroid binding protein and crosses the cell membrane, facilitated by a relative small size and lipophilic property. Inside the cell, maximum interaction with cytosolic glucocorticoid receptor (GR) occurs with the binding to a complex of chaperones that include immunophilin binding protein (FK506-BP) and heat shock proteins (HSP). Activation of the GC-GR unit results in its dissociation from the multi-protein chaperones. Both monomers and dimerized forms of GR-GC unitare translocated into the nucleus where they bind the responsive elements for transcription factors (TFRE) and the glucocorticoid responsive elements (GRE) respectively. The transcription factors are activator protein-1 (AP-1), nuclear factor-kB (NF-kB) and signal transducer and activator of transcription-5 (STAT5). The ultimate effects of this gene transcriptionsare inhibition of pro-inflammatory cytokines and downregulation of cellular proliferation (cell cycle arrest/ apoptosis).

Table 1: Pharmacodynamic inter-relationship of steroids and contemporary maintenance immunosuppressive agents in renal transplantation

\begin{tabular}{|c|c|c|c|}
\hline Steroids + Drugs & Mechanisms of action & Pros & Cons \\
\hline Tacrolimus (TAC) & $\begin{array}{l}\text { *Binds FKBP12 and inhibits calcineurin } \\
\text { dephosphorylation of NFAT, a transcrip- } \\
\text { tion factor (TF) for IL-2 synthesis. }\end{array}$ & $\begin{array}{l}\text { *TAC/MMF/steroids most effective main- } \\
\text { tenance ISA } \\
{ }^{*} \mathrm{GC} \text { supports Tregs/ graft tolerance } \\
{ }^{*} \mathrm{GC} \text { inhibits TF: AP-1 and NFKB } \\
\text { *Activate renal P-glycop/ cyt P450: } \\
\text { reduce nephrotoxicity }\end{array}$ & $\begin{array}{l}\text { *TAC diminishes IL-2 support for AICC } \\
\text { and graft tolerance } \\
\text { *TAC/MMF/GC may promote BK virus } \\
\text { infection } \\
\text { *GC + TAC promote NODAT/ Hyperten- } \\
\text { sion/ hyperlipemia }\end{array}$ \\
\hline Cyclosporine (CsA) & $\begin{array}{l}\text { *Binds cyclophillin and inhibits calci- } \\
\text { neurin dephosphorylation of NFAT, a TF } \\
\text { for IL-2 synthesis. }\end{array}$ & $\begin{array}{l}\text { *Similar to TAC but may be less } \\
\text { effective }\end{array}$ & $\begin{array}{l}\text { *Similar to TAC but more hyperlipemia } \\
\text { and less NODAT } \\
\text { *Increases serum MMF + toxicity }\end{array}$ \\
\hline Mycophenolate Mofetil (MMF) & $\begin{array}{l}\text { *Inhibits IMDH + progression of cell } \\
\text { cycle }\end{array}$ & $\begin{array}{l}\text { *Allows lower doses of CNI/ GC } \\
\text { *GC enhances UDPGT + decrease } \\
\text { toxicity } \\
{ }^{*} \mathrm{GC} \text { attenuates BM depression }\end{array}$ & $\begin{array}{l}\text { *Bone marrow depression } \\
{ }^{*} \text { CsA increases serum MMF + toxicity }\end{array}$ \\
\hline Sirolimus (SRL) & $\begin{array}{l}{ }^{*} \text { Binds FKBP12 + mTOR to arrest } \\
\text { growth cycle } \\
{ }^{*} \text { Anti-proliferative agent }\end{array}$ & $\begin{array}{l}\text { *Reduces non-melanoma skin cancer } \\
\text { *Survival of Tregs/ graft tolerance? }\end{array}$ & $\begin{array}{l}\text { *GC/RAP delay wound healing, cause } \\
\text { NODAT + hyperlipemia } \\
\text { *RAP delays graft function/ nephrotoxic- } \\
\text { ity/ proteinuria } \\
\text { *TAC/ RAP promote PTLD in EBV (-) } \\
\text { / TMA }\end{array}$ \\
\hline Belatacept & $\begin{array}{l}\text { CTLA4Ig: blocks co-stimulatory CD28 } \\
\text { receptor }\end{array}$ & $\begin{array}{l}\text { *Better short-term graft function vs. CsA } \\
{ }^{*} \text { GC+Belatacept: Less CV morbidity vs. } \\
\text { GC/CsA? }\end{array}$ & $\begin{array}{l}\text { *Promotes PTLD in EBV (-) } \\
\text { *Does not inhibit memory T cell } \\
\text { *More frequent early AR vs. CsA }\end{array}$ \\
\hline
\end{tabular}

AICD: Activation-Induced Cell Death, AP-1: Activated Protein-1, AR: Acute Rejection, BM: Bone Marrow, CD28-r: CD28 Receptor on T-lymphocyte, CNI: Calcineurin Inhibitors, CTLA-4Ig: Cytotoxic T Lymphocyte Antigen-4: cyt P450: Cytochrome P450, FKBP-12: FK506-Binding Protein 12, dePP: Dephosphorylation, IMDH: Inosine Monophosphate Dehydrogenase; ISA: Immunosuppressive Agents, EBV (-): Epstein Barr Virus Seronegative, MMF: Mycophenolate Mofetil, Mtor: Mammalian Target of Rapamycin, NFAT: Nuclear Factor of Activated T cells, NF $\square$ B: Nuclear Factor Kappa B, NODAT: New Onset Diabetes Mellitus After Transplant, P-glycop: P-Glycoprotein Efflux System, PTLD: Post Transplant Lymphoproliferative Disorder, TAC: Tacrolimus, TF: Transcription Factor, TMA: Thrombotic Microangiopathy, UDGT: Uridine Diphosphate Glucuronosyl-transferase

(iNOS) [63]. Glucocorticoid inhibits both T- and B cell immune responses but produces a greater impact on $\mathrm{T}$-cell function. Although universally expressed in most cells, glucocorticoid receptors are less pronounced in non-thymic cells. On the contrary, steroid treatment of the thymic lymphocytes produce accelerated apoptosis by induction of $\mathrm{C} 3$ isoform of GC receptor mRNA. Furthermore, double-positive thymocytes (CD4+CD8+) and natural killer $\mathrm{T}$ cells are more susceptible to glucocorticoidinduced cell death (GICD) [64].

\section{Steroid and allograft tolerance}

Glucocorticoid treatment tilts the balance in favor of grafttolerance by promoting the regulatory [Foxp3+ CD4+ CD25+] T-cells while inhibiting the cytotoxicity of T-effector cells $[65,66]$. Similarly, compared with the staining for IL-17 cytokines, individuals with renal histological specimen that expresses FOXP3 had lower frequency of steroid-resistant rejection events $[66,67]$. In addition, maintenance dose of steroids after a successful treatment of an acute rejection with pulse GC therapy results in a lower occurrence of a 
second episode [44]. On the contrary, by promoting a non-selective down-regulation of IL-2 receptor activity, CNI fails to preserve the tolerogenic effect of the regulatory T-cells [65].

\section{Mechanisms of Steroid Adverse Effects}

Attempts to eliminate steroid and/ or CNI were motivated by the disproportionate impact of cardiovascular disease on the mortality rate of KTR with functioning graft $[4,68]$. Adverse effects of prolonged steroid use include hyperlipidemia, growth retardation, obesity, insulin resistance, hypertension, and bone diseases. By promoting apoptosis of plasmacytoid dendritic cells [PDC] and reducing the synthesis of interferon-alfa cytokine, steroid induction therapy increases the susceptibility of transplant recipients to opportunistic viral infection predominantly CMV and BK virus $[69,70]$. Steroid role in oxidative stress: While steroid (induction) modulates oxidative inflammation that results from IRI which is promoted by transplant surgery, its use as maintenance treatment in high doses may produce adverse carbonylation[catabolism] of the skeletal muscle protein $[71,72]$. This is partly due to activation of proteolytic ubiquitinproteasome pathway which is induced by up regulating the expression of atrogin-1 and MuRF-1 genes [73,74]. Fortunately, such untoward effect is mitigated by endogenous elaboration of IGF-I which inhibits FOXO gene and decreases PI3-kinase signal transduction [74]. In addition, there is adaptive increase in the renal expression of tocopherol ( $\alpha$ ) transfer protein gene, which in turn promotes the recycling of anti-oxidative vitamin $\mathrm{E}[73,75]$.

\section{Steroid and hypertension}

Due to impaired glomerular filtration, pre-existing (donor) vasculopathy and vasocostrictive effect of CNI, hypertension is common in the first few days of kidney transplantation [76,77]. Loading dose of steroids as used for induction during transplant surgery may augment such hypertensive events. Excess intake of salt decreases endothelial synthesis of protective nitric oxide while raising the vasoconstrictive substance, asymmetric dimethyl arginine (ADMA) [76]. However, contrary to the theoretical expectation, steroid withdrawal protocol fails to attenuate the long-term prevalence of post-transplant hypertension. The principal mediator of steroidinduced hypertension is the glucocorticoid receptor activity [73]. This is demonstrated in an experimental mouse model of chronic steroid infusion that showed no significant change in the renal expression of mineral corticoid target genes including ENaC, Kras, and Nedd4 [73]. In addition, there was no evidence for tubular sodium reabsorption, potassium wasting or elevation in the plasma renin activity. Instead, GC effect increases the response to angiotensin II, which in turn enhances the synthesis of its (GC) receptors on vascular smooth muscle cell. It promotes hyper-filtration which causes an increase in the net sodium excretion [73]. Furthermore, there is (GC) reduction in the endothelial cell release of neuronal NO by the inactivation of protein kinase C signaling [78,79]. Finally, validating the effect of endothelial GC receptor, its knock-out mouse model failed to develop hypertension in response to dexamethasone infusion [80].

\section{Steroids and NODAT}

Due to the lower doses of steroid used in recent times, there is a falling incidence rate of new-onset diabetes mellitus after transplantation (NODAT) [81]. A study showed there is $5 \%$ risk of developing diabetes mellitus for every $0.01 \mathrm{mg} / \mathrm{kg} /$ day increase in prednisolone dose [82]. Similarly, there is $42 \%$ greater risk of developing NODAT in patients placed on steroid-based regimen over a period of three years [83]. Most likely there are additive effects from other agents. Hence calcineurin inhibitor, sirolimus and steroids are estimated to account for $74 \%$ incidence of NODAT. New onset diabetes mellitus has been associated with poorer graft survival and a three-fold higher risk of sustaining adverse CV events [84].

Risk factors of NODAT: Predisposing factors of NODAT include genetic susceptibility, deceased organ donation, older age ( $>40$ years), male gender, ethnic minority, exogenous obesity, hyperlipidemia, hypertension, hepatitis $\mathrm{C}$ infection, previous transplants, and $\geq$
3 HLA class 1 mis-matches [85]. Similarly, greater number of metabolic syndrome components correlates with the probability of developing NODAT. Hence pre-transplant screening for the detection of modifiable metabolic events is an appropriate preventive strategy. Unfortunately, renal allograft survival is often limited by the occurrence of chronic immunologic injury that promotes a pro-inflammatory milieu which in turn increases susceptibility to metabolic disorders. This relationship is demonstrated in transplant patients with single nucleotide polymorphism for gene encoding interferon gamma cytokines and higher incidence of steroid-induced insulin resistance [86].

Mechanism of steroid-induced NODAT: Glucocorticoid produces hyperglycemia by inducing the transcription genes for hepatic gluconeogenic enzymes. Hyperglycemia in turn inhibits pancreatic beta cells, an effect that is readily overcome by a parallel event of excessive (circulating) insulin $[87,88]$. However the latter is invariably cytotoxic. For instance, insulin stimulation of its receptor prevents translocation of FoxO1 into the nucleus of beta cells, which in turn promotes apoptosis by the suppression of Pdx1 gene [89]. Such untoward effect may be potentiated by mitochondrial toxicity that results from concurrent use of CNI, particularly tacrolimus [90]. Ultimately, persistent stimulation of a fewer number of beta cells causes pancreatic cell hypertrophy [91].

It is pertinent to mention that in addition to risk categorization by epidemiologic profiles, assessment of genetic susceptibility are potential tools for (the) selection of patients that may benefit from individualized therapeutic approach. In this regard, genes that are associated with greater risk of developing NODAT are vitamin D receptor (VDR), hepatocyte nuclear factor (HNF1A), DUSP9 locus on X chromosome, and voltage-gated potassium channel (KCNQ1) $[92,93]$. Because most trials on this subject are not randomized, large scale studies will be required for the validation of this approach.

\section{Steroids and dyslipidemia}

Partly due to intensity of immunosuppression, dyslipidemia occurs within the first year in more than $80 \%$ of adult renal allograft recipients [94]. Patients who had hyperlipidemia before engraftment are more likely to have a persistent disorder after transplantation [95]. Interestingly, the most significant risk factor is the cumulative dose of corticosteroid [96]. Chronic steroid use increases free fatty acid synthetase and up-regulates hepatic synthesis of very low-density lipoprotein (VLDL) [96]. It also reduces the synthesis of low-density lipoprotein (LDL) receptor and inhibits the enzymatic activity of lipoprotein lipase [97]. The sum effect is an increase in the serum total cholesterol, high serum triglyceride, and elevated level of VLDL $[98,99]$. However, depicting a striking similarity with HD patients, due to a concurrent reduction in Apo-A lipid fraction, elevated level of plasma high-density lipoprotein (HDL) cholesterol does not confer a cardiovascular benefit $[95,100]$. In addition, chronic steroid treatment potentiates the lipemic effects of both CsA and sirolimus [27,101-103]. Because CsA is transported in the circulation by LDL cholesterol particles, prednisolone enhances its intracellular uptake by LDL receptors [101].

Supporting the synergistic role of steroids, co-culture of hepatic cells in a medium containing CsA and palmitic acid causes mitochondrial dysfunction via the activation of c-Jun N-terminal kinase (JNK) [102]. In comparison, it appears tacrolimus produces less lipid disturbances [101]. Similarly, 2 weeks after adding sirolimus to the regimen of CsA and steroids, it causes a dose-dependent increase in total plasma cholesterol, LDL, triglyceride, and ApoB100[97] [103]. Normal lipid levels are restored by about 4 weeks after discontinuation of the drug [103]. In animal model, sirolimus impairs hydrolysis of circulating triglyceride, cellular uptake of fatty acid, and lipid synthesis (lipin 1) by down-regulation of peroxisome proliferator-activated receptor- $\gamma 2$ (PPAR- $\gamma$ 2) [104]. Additional mechanism of action is by the blocking of modulatory effects of mTORC1 on adipogenesis through the Akt-mediated phosphorylation of tuberous sclerosis complex 2 [104]. 


\section{Steroids and vascular thrombosis}

Chronic steroid treatment promotes thrombotic vascular disease by increasing the serum concentration of plasminogen activator inhibitor antigen (PAI-1) [105]. This relationship is demonstrated in a study that showed a significant reduction in the stimulated fibrinolytic capacity in heart transplant patients who were treated with steroid-based protocol [105]. By combining steroids with CsA, this process may be aggravated by endothelial injury that is promoted by the calcineurin inhibitor [106]. Thus experimental rat model of aortic allograft developed proliferative hyaline thickening of the vascular wall within 2 months of CsA treatment but not with the use of AZA [106]. Similarly, sirolimus may potentiate chronic steroid-induced vasculopathy [107]. It inhibits smooth muscle cell hyperplasia by up-regulating the gene for the transcription of nitric oxide synthase [108]; and reduces synthesis of vascular endothelial growth factor (VEGF) in tumor cell lines [109]. On the other hand, as previously mentioned, loading dose of steroids [during transplant surgery] may be potentially beneficial to endothelial health. It reverses tacrolimus up-regulation of pro-oxidative, asymmetric dimethyl-arginine and endothelial nitric oxide synthase [110].

\section{Steroids and bone metabolism}

Steroids and linear growth: The initial wave of clinical trial on steroid minimization was conducted in pediatric population out of concern for its negative impact on longitudial skeletal growth [111] A two-year randomized trial of late steroid withdrawal ( $>3$ months) using cyclosporine and mycophenolate mofetil as maintenance therapy showed a positive catch-up growth and a favorable metabolic impact $[105,112]$. Similar result was obtained in children younger than 5 years of age while improved nutritional status was observed in steroid-free pediatric recipients of intestinal transplant [106;113].

Steroids and bone disease: Despite normal serum calcium, phosphorous and intact PTH, osteitisfibrosa, osteomalacia, and adynamic bone disease are common findings on bone biopsy obtained from transplant recipients [114]. There is positive correlation between cumulative steroid dose, loss of bone mineral density and the incidence of pathological fracture [115]. In addition to steroid use, delayed restoration of parathyroid gland, metabolic acidosis, vitamin $\mathrm{D}$ deficiency, and inadequate graft function may accelerate bone disease [114]. Dexamethasone inhibits renal tubular reabsorption of calcium and/ or phosphorous by modulation of serum glucocorticoid kinase [116,117], $\mathrm{Na}+\mathrm{H}+$ exchanger [118] and $\mathrm{Na}-\mathrm{Pi} 4$ co-transporter [119]. It decreases bone-forming osteoblastic cells, increases apoptosis of osteocytes, and attenuates both insulinlike growth factor-1 [IGF-1] and transforming growth factor-b (TGF-b) [120].

Furthermore, it stimulates osteoprotegerin ligand [OPG-L] and causes inactivation of its soluble neutralizing receptor, osteoprotegerin [OPG] [120]. Lower doses of steroids, alternate-daily regimen, and correction of hypogonadism may potentially ameliorate the severity of bone disease [121]. Indeed patients on GC withdrawal protocol sustain a net gain in BMD; a benefit that was more pronounced in patients with severe kidney disease [122]. There are limited data on the safety and effectiveness of bisphosphonates in solid organ transplantation. Its use in liver transplant recipients was associated with the preservation of trabecular bone mineralization but there was no (beneficial) therapeutic effect on the cortical bone mass [123].

\section{Summary}

We've achieved a remarkable stride in the provision of targeted immunosuppression against alloreactive $\mathrm{T}$ lymphocytes. This has reduced the attrition rate of renal allograft in the first year to the barest minimum; about $5-10 \%$. Nevertheless inadequacy of the currently available ISA has led to increasing relevance of chronic antibody mediated injury as a potential reason for late onset graft losses. The broad-spectrum activity of steroids against B-and T- lymphocyte immune responses has played a beneficial modulatory role over the years. However, many transplant patients have paid a huge price in the form of adverse metabolic effects and CV complications. To this end, it is commendable that steroid sparing regimen have been successfully used in low risk transplant recipients. Steroid avoidance in high immunological risk recipients often necessitates [induction] treatment with potentially toxic lymphocyte depleting agents. Finally, it is very likely that steroids will continue to play a significant role in the prevention and treatment of immune mediated allograft injury. In the near future, steroids may be most useful in the context of risk categorization to identify drugs that are best suited for individual patients.

\section{Acknowledgement}

The author thank Dr Renee Gardner, Dr Fasika Tedla, Dr Costa Dimitriades, Dr Ricardo Sorensen, Dr Matti Vehaskari and Dr Susan Gottesman for their assistance with proofreading.

\section{References}

1. Wiebe C, Gibson IW, Blydt-Hansen TD, Karpinski M, Ho J, et al. (2012) Evolution and clinical pathologic correlations of de novo donor-specific HLA antibody post kidney transplant. Am J Transplant 12: 1157-1167.

2. Halloran PF (2004) Immunosuppressive drugs for kidney transplantation. N Engl J Med 351: 2715-2729.

3. DUNEA G, NAKAMOTO S, STRAFFON RA, FIGUEROA JE, VERSACI AA et al. (1965) RENAL HOMOTRANSPLANTATION IN 24 PATIENTS. Br Med J 1: 7-13.

4. Höcker B, Tönshoff B (2011) Calcineurin inhibitor-free immunosuppression in pediatric renal transplantation: a viable option? Paediatr Drugs 13: 49-69.

5. Lamb KE, Lodhi S, Meier-Kriesche HU (2011) Long-term renal allograft survival in the United States: a critical reappraisal. Am J Transplant 11: 450-462.

6. Andreoni KA, Brayman KL, Guidinger MK, Sommers CM, Sung RS (2007) Kidney and pancreas transplantation in the United States, 1996-2005. Am J Transplant 7: 1359-1375.

7. Zhang X, Huang H, Han S, Fu S, Wang $L$ (2013) Is it safe to withdraw steroids within seven days of renal transplantation? Clin Transplant 27: 1-8.

8. Pascual J, Zamora J, Galeano C, Royuela A, Quereda C (2009) Steroid avoidance or withdrawal for kidney transplant recipients. Cochrane Database Syst Rev: CD005632.

9. Saull HE, Enderby CY, Gonwa TA, Wadei HM (2015) Comparison of alemtuzumab versus antithymocyte globulin induction therapy in primary nonsensitized renal transplant patients treated with rapid steroid withdrawal. Clin Transplant : 10.1111/ctr.12532.

10. Noureldeen T, Albekioni Z1, Machado L1, Muddana N1, Marcus RJ1, et al. (2014) Alemtuzumab induction and antibody-mediated rejection in kidney transplantation. Transplant Proc 46: 3405-3407.

11. Brennan DC, Daller JA, Lake KD, Cibrik D, Del Castillo D, et al. (2006) Thymoglobulin Induction Study Group. Rabbit antithymocyte globulin versus basiliximab in renal transplantation. N Engl J Med 355: 1967-1977.

12. Webster AC, Playford EG, Higgins G, Chapman JR, Craig JC (2004) Interleukin 2 receptor antagonists for renal transplant recipients: a metaanalysis of randomized trials. Transplantation 77: 166-176.

13. Schmidt SC, Hamann S, Langrehr JM, Höflich C, Mittler J, et al. (2007) Preoperative high-dose steroid administration attenuates the surgical stress response following liver resection: results of a prospective randomized study. J Hepatobiliary Pancreat Surg 14: 484-492.

14. Knight SR, Morris PJ (2010) Steroid avoidance or withdrawal after renal transplantation increases the risk of acute rejection but decreases cardiovascular risk. A meta-analysis. Transplantation 89: 1-14.

15. Sinclair NR (1992) Canadian Multicenter Transplant Study Group. Low-dose steroid therapy in cyclosporine-treated renal transplant recipients with wellfunctioning graft. CMAJ 147: 645-657.

16. Vincenti F, Schena FP, Paraskevas S, Hauser IA, Walker RG, et al. (2008) A randomized, multicenter study of steroid avoidance, early steroid withdrawal or standard steroid therapy in kidney transplant recipients. Am J Transplant 8: 307-316.

17. Rush D (2013) The impact of calcineurin inhibitors on graft survival. Transplant Rev (Orlando) 27: 93-95.

18. Sandrini S, Aslam N, Tardanico R, Setti G, Bossini N, et al. (2012) Tacrolimus versus cyclosporine for early steroid withdrawal after renal transplantation. $J$ Nephrol 25: 43-49.

19. Bakar F, Keven K, Dogru B, Aktan F, Erturk S, et al. (2009) Low-density lipoprotein oxidizability and the alteration of its fatty acid content in renal transplant recipients treated with cyclosporine/tacrolimus. Transplant Proc 41: $1630-1633$. 
20. Webster AC, Woodroffe RC, Taylor RS, Chapman JR, Craig JC (2005) Tacrolimus versus ciclosporin as primary immunosuppression for kidney transplant recipients: Meta-analysis and meta-regression of randomised trial data. BMJ 331: 810

21. Lloberas N, Torras J, Alperovich G, Cruzado JM, Giménez-Bonafé P, et al. (2008) Different renal toxicity profiles in the association of cyclosporine and tacrolimus with sirolimus in rats. Nephrol Dial Transplant 23: 3111-3119.

22. Wang R, Xu Y, Wu J, Wang Y, He Q, et al. (2013) Reduced-dose cyclosporine with mycophenolate mofetil and prednisone significantly improves the longterm glomerular filtration rate and graft survival. Intern Med 52: 947-953.

23. Naesens M, Kuypers DR, Sarwal M (2009) Calcineurin inhibitor nephrotoxicity. Clin J Am Soc Nephrol 4: 481-508.

24. Metalidis C, Lerut E, Naesens M, Kuypers DR (2011) Expression of CYP3A5 and $\mathrm{P}$-glycoprotein in renal allografts with histological signs of calcineurin inhibitor nephrotoxicity. Transplantation 91: 1098-1102.

25. Ekberg H, Tedesco-Silva H, Demirbas A, Vítko S, Nashan B, et al. (2007) Reduced exposure to calcineurin inhibitors in renal transplantation. $\mathrm{N} \mathrm{Engl} J$ Med 357: 2562-2575

26. Chhabra D, Skaro Al, Leventhal JR, Dalal P, Shah G, et al. (2012) Long-term kidney allograft function and survival in prednisone-free regimens: tacrolimus/ mycophenolate mofetil versus tacrolimus/sirolimus. Clin J Am Soc Nephrol 7: 504-512.

27. Ponticelli C (2014) The pros and the cons of mTOR inhibitors in kidney transplantation. Expert Rev Clin Immunol 10: 295-305.

28. Pape L, Ahlenstiel T (2014) mTOR inhibitors in pediatric kidney transplantation Pediatr Nephrol 29: 1119-1129.

29. Knight SR, Russell NK, Barcena L, Morris PJ (2009) Mycophenolate mofetil decreases acute rejection and may improve graft survival in renal transplant recipients when compared with azathioprine: a systematic review. Transplantation 87: 785-794.

30. Pazik J, OÅ,dak M, Lewandowski Z, PodgÃ $\tilde{A}^{3}$ ska M, Sitarek E, et al. (2013) Uridine diphosphate glucuronosyltransferase 2B7 variant p. His268Tyr as a predictor of kidney allograft early acute rejection. Transplant Proc 45: 15161519.

31. Vacher-Coponat H, Moal V, Indreies M, Purgus R, Loundou A, et al. (2012) A randomized trial with steroids and antithymocyte globulins comparing cyclosporine/azathioprine versus tacrolimus/mycophenolatemofetil (CATM2) in renal transplantation. Transplantation 93: 437-443.

32. Gandolfo MT, Jang HR, Bagnasco SM, Ko GJ, Agreda P, et al. (2010) Mycophenolate mofetil modifies kidney tubular injury and Foxp3+ regulatory $T$ cell trafficking during recovery from experimental ischemia-reperfusion. Transpl Immunol 23: 45-52.

33. Renner FC, Dietrich H, Bulut N, Celik D, Freitag E, et al. (2013) The risk of polyomavirus-associated graft nephropathy is increased by a combined suppression of CD8 and CD4 cell-dependent immune effects. Transplan Proc 45: 1608-1610.

34. Rostaing L, Vincenti F, Grinyó J, Rice KM, Bresnahan B, et al. (2013) Long term belatacept exposure maintains efficacy and safety at 5 years: results from the long-term extension of the BENEFIT study. Am J Transplant 13 2875-2883.

35. Soveri I, Snyder J, Holdaas H, Holme I, Jardine AG, et al. (2013) The external validation of the cardiovascular risk equation for renal transplant recipients applications to BENEFIT and BENEFIT-EXT trials. Transplantation 95: 142 147.

36. Masson P, Henderson L, Chapman JR, Craig JC, Webster AC (2014) Belatacept for kidney transplant recipients. Cochrane Database Syst Rev 11 CD010699.

37. Kidney Disease: Improving Global Outcomes (KDIGO) Transplant Work Group (2009) KDIGO clinical practice guidelines for the care of kidney transplant recipients. American Journal of Transplantation 9: S1-S155.

38. Gourishankar S1, Grebe SO, Mueller TF (2013) Prediction of kidney graft failure using clinical scoring tools. Clin Transplant 27: 517-522.

39. Padiyar A, Augustine JJ, Bodziak KA, Aeder M, Schulak JA, et al. (2010) Influence of African-American ethnicity on acute rejection after early steroid withdrawal in primary kidney transplant recipients. Transplant Proc 42: 16431647.

40. Humar A, Gillingham K, Kandaswamy R, Payne W, Matas A (2007) Steroid avoidance regimens: a comparison of outcomes with maintenance steroids versus continued steroid avoidance in recipients having an acute rejection episode. Am J Transplant 7: 1948-1953.

41. Cosio FG, Grande JP, Wadei H, Larson TS, Griffin MD, et al. (2005) Predicting subsequent decline in kidney allograft function from early surveillance biopsies. Am J Transplant 5: 2464-2472.

42. Mitchison NA1 (2004) T-cell-B-cell cooperation. Nat Rev Immunol 4: 308-312.
43. Seissler N, Schmitt E, Hug F, Sommerer C, Zeier M, et al. (2012) Methylprednisolone treatment increases the proportion of the highly suppressive HLA-DR(+)-Treg-cells in transplanted patients. Transpl Immunol 27: $157-561$.

44. Tornatore KM, Biocevich DM, Reed K, Tousley K, Singh JP, et al. (1995) Methylprednisolone pharmacokinetics, cortisol response, and adverse effects in Black and White renal transplant recipients. Transplantation 59: 649-795.

45. Ordonez L, Bernard I, Chabod M, Augusto JF, Lauwers-Cances V, et al. (2013) A higher risk of acute rejection of human kidney allografts can be predicted from the level of CD45RC expressed by the recipients' CD8 T cells. PLoS One 8: e69791.

46. Takeuchi $\mathrm{H}$, Matsuno N, Hirano T, Gulimire M, Hama K, et al. (2011) Steroid withdrawal based on lymphocyte sensitivity to endogenous steroid in renal transplant recipients. Biol Pharm Bull 34: 1578-1583.

47. Shooshtarizadeh T, Mohammadali A, Ossareh S, Ataipour Y (2013) Relation between pretransplant serum levels of soluble CD30 and acute rejection during the first 6 months after a kidney transplant. Exp Clin Transplant 11: 229-233.

48. Staatz CE, Goodman LK, Tett SE (2010) Effect of CYP3A and ABCB1 single nucleotide polymorphisms on the pharmacokinetics and pharmacodynamics of calcineurin inhibitors: Part I. Clin Pharmacokinet 49: 141-175.

49. Ferraris JR, Argibay PF, Costa L, Jimenez G, Coccia PA, et al. (2011) Influence of CYP3A5 polymorphism on tacrolimus maintenance doses and serum levels after renal transplantation: age dependency and pharmacological interaction with steroids. Pediatr Transplant 15: 525-532.

50. Lam S, Partovi N, Ting LS, Ensom MH (2008) Corticosteroid interactions with cyclosporine, tacrolimus, mycophenolate, and sirolimus: fact or fiction? Ann Pharmacother 42: 1037-1047.

51. Stratta P, Quaglia M, Cena T, Antoniotti R, Fenoglio R, et al. (2012) The interactions of age, sex, body mass index, genetics, and steroid weight-based doses on tacrolimus dosing requirement after adult kidney transplantation. Eur J Clin Pharmacol 68: 671-680.

52. Lecoq L, Vincent P, Lavoie-Lamoureux A Lavoie JP (2009) Genomic and non-genomic effects of dexamethasone on equine peripheral blood neutrophils. Vet Immunol Immunopathol 128: 126-131.

53. Pérez MH, Mallinson D, Cormack J, Mutungi G (2013) A membrane glucocorticoid receptor mediates the rapid/non-genomic actions of glucocorticoids in mammalian skeletal muscle fibres. J Physiol 591: 51715185.

54. Hafezi-Moghadam A, Simoncini T, Yang Z, Limbourg FP, Plumier JC, et al. (2002) Acute cardiovascular protective effects of corticosteroids are mediated by non-transcriptional activation of endothelial nitric oxide synthase. Nat Med 8: $473-479$.

55. Cato AC, Nestl A, Mink S (2002) Rapid actions of steroid receptors in cellular signaling pathways. Sci STKE 2002: re9.

56. Perretti M, Flower RJ (1994) Cytokines, glucocorticoids and lipocortins in the control of neutrophil migration. Pharmacol Res 30: 53-59.

57. Yu DT, Clements PJ, Paulus HE, Peter JB, Levy J, et al. (1974) Human lymphocyte subpopulations. Effect of corticosteroids. J Clin Invest 53: 565-571.

58. Shoenfeld Y, Gurewich Y, Gallant LA, Pinkhas J (1981) Prednisone-induced leukocytosis. Influence of dosage, method and duration of administration on the degree of leukocytosis. Am J Med 71: 773-778.

59. Revollo JR, Cidlowski JA (2009) Mechanisms generating diversity in glucocorticoid receptor signaling. Ann N Y Acad Sci 1179: 167-178.

60. Müller N, Fischer HJ, Tischner D, van den Brandt J, Reichardt HM (2013) Glucocorticoids induce effector T cell depolarization via ERM proteins, thereby impeding migration and APC conjugation. J Immunol 190: 4360-4370.

61. Shaffer MH, Dupree RS, Zhu P, Saotome I, Schmidt RF, et al. (2009) Ezrin and moesin function together to promote $T$ cell activation. J Immunol 182: $1021-1032$

62. King EM, Chivers JE, Rider CF, Minnich A, Giembycz MA, et al. (2013) Glucocorticoid repression of inflammatory gene expression shows differential responsiveness by transactivation- and transrepression-dependent mechanisms. PLoS One; 8: e53936.

63. Kleinert H, Euchenhofer C, Ihrig-Biedert I, Förstermann U (1996) Glucocorticoids inhibit the induction of nitric oxide synthase II by downregulating cytokine-induced activity of transcription factor nuclear factorkappa B. Mol Pharmacol 49: 15-21.

64. Boldizsár F, Pálinkás L, Czömpöly T, Bartis D, Németh P, et al. (2006) Low glucocorticoid receptor (GR), high Dig2 and low Bcl-2 expression in double positive thymocytes of BALB/c mice indicates their endogenous glucocorticoid hormone exposure. Immunobiology 211: 785-796.

65. Dummer CD, Carpio VN, Gonçalves LF, Manfro RC, Veronese FV (2012) FOXP3+ regulatory $T$ cells: from suppression of rejection to induction of renal allograft tolerance. Transpl Immunol 26: 1-10. 
66. Franzese O, Mascali A, Capria A, Castagnola V, Paganizza L, et al. (2013) Regulatory $T$ cells in the immunodiagnosis and outcome of kidney allograft rejection. Clin Dev Immunol 2013: 852395.

67. Chung BH, Oh HJ, Piao SG, Hwang HS, Sun IO, et al. (2012) Clinical significance of the ratio between FOXP3 positive regulatory $\mathrm{T}$ cell and interleukin-17 secreting cell in renal allograft biopsies with acute T-cellmediated rejection. Immunology 136: 344-351.

68. Morales JM, Marcén R, del Castillo D, Andres A, Gonzalez-Molina M, et al. (2012) Risk factors for graft loss and mortality after renal transplantation according to recipient age: a prospective multicentre study. Nephrol Dia Transplant 27: iv39-iv46.

69. Boor PP, Metselaar HJ, Mancham S, Tilanus HW, Kusters JG, et al. (2006) Prednisolone suppresses the function and promotes apoptosis of plasmacytoid dendritic cells. Am J Transplant 6: 2332-2341.

70. Borni-Duval C1, Caillard S, Olagne J, Perrin P, Braun-Parvez L, et al. (2013) Risk factors for BK virus infection in the era of therapeutic drug monitoring Transplantation 95: 1498-1505.

71. Turgay M, Turgay F, Devrim E, Kucuksahin O, Caydere M, et al. (2012) The effects of dexamethasone on oxidant/antioxidant status in kidneys of rats administered mercuric chloride. Bratisl Lek Listy 113: 10-13.

72. Saidi RF, Chang J, Verb S, Brooks S, Nalbantoglu I, et al. (2007) The effect of methylprednisolone on warm ischemia-reperfusion injury in the liver. Am J Surg 193: 345-347.

73. Bailey MA, Mullins JJ, Kenyon CJ (2009) Mineralocorticoid and glucocorticoid receptors stimulate epithelial sodium channel activity in a mouse model of Cushing syndrome. Hypertension 54: 890-896.

74. Schakman O, Kalista S, Barbé C, Loumaye A, Thissen JP (2013) Glucocorticoid-induced skeletal muscle atrophy. Int J Biochem Cell Biol 45 : 2163-2172.

75. Mardones P, Strobel P, Miranda S, Leighton F, Quiñones V, et al. (2002) Alpha-tocopherol metabolism is abnormal in scavenger receptor class $B$ type I (SR-BI)-deficient mice. J Nutr 132: 443-449.

76. Toda N, Arakawa K (2011) Salt-induced hemodynamic regulation mediated by nitric oxide. J Hypertens 29: 415-424.

77. Mangray M, Vella JP (2011) Hypertension after kidney transplant. Am J Kidney Dis 57: 331-341.

78. Ong SL, Whitworth JA (2011) How do glucocorticoids cause hypertension role of nitric oxide deficiency, oxidative stress, and eicosanoids. Endocrinol Metab Clin North Am 40: 393-407, ix.

79. Aras-López R, Xavier FE, Ferrer M, Balfagón G (2009) Dexamethasone decreases neuronal nitric oxide release in mesenteric arteries from hypertensive rats through decreased protein kinase $\mathrm{C}$ activation. Clin Sci (Lond) 117: 305-312.

80. Baum M, Moe OW (2008) Glucocorticoid-mediated hypertension: does the vascular smooth muscle hold all the answers? J Am Soc Nephrol 19: 1251-1253.

81. Heisel O, Heisel R, Balshaw R, Keown P (2004) New onset diabetes mellitus in patients receiving calcineurin inhibitors: a systematic review and metaanalysis. Am J Transplant 4: 583-595.

82. Hjelmesaeth J, Hartmann A, Kofstad J, Stenstrøm J, Leivestad T, et al. (1997) Glucose intolerance after renal transplantation depends upon prednisolone dose and recipient age. Transplantation 64: 979-983.

83. Luan FL, Steffick DE, Ojo AO (2011) New-onset diabetes mellitus in kidney transplant recipients discharged on steroid-free immunosuppression. Transplantation 91: 334-341.

84. Cosio FG, Kudva Y, van der Velde M, Larson TS, Textor SC, et al. (2005) New onset hyperglycemia and diabetes are associated with increased cardiovascular risk after kidney transplantation. Kidney Int 67: 2415-2421.

85. Bergrem HA, Valderhaug TG, Hartmann A, Bergrem H, Hjelmesaeth J, et al. (2010) Glucose tolerance before and after renal transplantation. Nephrol Dial Transplant 25: 985-992.

86. Babel N, Cherepnev G, Kowalenko A, Horstrup J, Volk HD, et al. (2004) Nonimmunologic complications and gene polymorphisms of immunoregulatory cytokines in long-term renal transplants. Kidney Int 66: 428-432.

87. Vadlamudi S, Hiremagalur BK, Tao L, Kalhan SC, Kalaria RN, et al. (1993) Long-term effects on pancreatic function of feeding a $\mathrm{HC}$ formula to rats during the preweaning period. Am J Physiol 265: E565-571.

88. Cernea S, Dobreanu M (2013) Diabetes and beta cell function: from mechanisms to evaluation and clinical implications. Biochem Med (Zagreb) 23: $266-280$

89. Kitamura T, Ido Kitamura Y (2007) Role of FoxO Proteins in Pancreatic beta Cells. Endocr J 54: 507-515.

90. Rostambeigi N, Lanza IR, Dzeja PP, Deeds MC, Irving BA, et al. (2011) Unique cellular and mitochondrial defects mediate FK506-induced islet $~^{2}$-cell dysfunction. Transplantation 91: 615-623.
91. Choi SB, Jang JS, Hong SM, Jun DW, Park S (2006) Exercise and dexamethasone oppositely modulate beta-cell function and survival via independent pathways in 90\% pancreatectomized rats. J Endocrinol 190: 471-482.

92. Li L1, Wu B, Liu JY, Yang LB (2013) Vitamin D receptor gene polymorphisms and type 2 diabetes: a meta-analysis. Arch Med Res 44: 235-241.

93. Voight BF, Scott LJ, Steinthorsdottir V, Morris AP, Dina C, et al. (2010) Twelve type 2 diabetes susceptibility loci identified through large-scale association analysis. Nat Genet 42: 579-589.

94. Spinelli GA, Felipe CR, Park SI, Mandia-Sampaio EL, Tedesco-Silva H, et al. (2011) Lipid profile changes during the first year after kidney transplantation: risk factors and influence of the immunosuppressive drug regimen. Transplant Proc 43: 3730-3737.

95. Razeghi E, Shafipour M, Ashraf H, Pourmand G (2011) Lipid disturbances before and after renal transplant. Exp Clin Transplant 9: 230-235.

96. Claes K, Meier-Kriesche HU, Schold JD, Vanrenterghem Y, Halloran PF, et al. (2012) Effect of different immunosuppressive regimens on the evolution of distinct metabolic parameters: evidence from the Symphony study. Nephrol Dial Transplant 27: 850-857.

97. Han CC, Wang JW, Pan ZX, Tang H, Xiang SX, et al. (2013) Effect of cholesterol on lipogenesis and VLDL-TG assembly and secretion in goose primary hepatocytes. Mol Cell Biochem 374: 163-172.

98. Ferraris JR, Pasqualini T, Alonso G, Legal S, Sorroche P, et al. (2007) Effects of deflazacort vs. methylprednisone: a randomized study in kidney transplant patients. Pediatr Nephrol 22: 734-741.

99. Vanrenterghem $Y$, van Hooff JP, Squifflet JP, Salmela K, Rigotti $P$, et al (2005) European Tacrolimus/MMF Renal Transplantation Study Group. Minimization of immunosuppressive therapy after renal transplantation: results of a randomized controlled trial. Am J Transplant 5: 87-95.

100. Kobayashi N, Okubo M, Marumo F, Uchida H, Endo T, et al. (1983) De novo development of hypercholesterolemia and elevated high-density lipoprotein cholesterol: apoprotein A-I ratio in patients with chronic renal failure following kidney transplantation. Nephron 35: 237-240.

101. Gueguen Y, Ferrari L, Souidi M, Batt AM, Lutton C, et al. (2007) Compared effect of immunosuppressive drugs cyclosporine $A$ and rapamycin on cholesterol homeostasis key enzymes CYP27A1 and HMG-CoA reductase. Basic Clin Pharmacol Toxicol 100: 392-397.

102. Derfler K, Hayde M, Heinz G, Hirschl MM, Steger G, et al. (1991) Decreased postheparin lipolytic activity in renal transplant recipients with cyclosporin $\mathrm{A}$ Kidney Int 40: 720-727.

103. Morrisett JD, Abdel-Fattah G, Kahan BD (2003) Sirolimus changes lipid concentrations and lipoprotein metabolism in kidney transplant recipients. Transplant Proc 35: 143S-150S.

104. Houde VP, Brûlé S, Festuccia WT, Blanchard PG, Bellmann K, et al. (2010) Chronic rapamycin treatment causes glucose intolerance and hyperlipidemia by upregulating hepatic gluconeogenesis and impairing lipid deposition in adipose tissue. Diabetes 59: 1338-1348.

105. Sartori TM, Maurizio PG, Sara P, Ugolino L, Annalisa A, et al. (1999) Relation between long-term steroid treatment after heart transplantation, hypofibrinolysis and myocardial microthrombi generation.J Heart Lung Transplant 18: 693-700.

106. Mennander A, Tiisala S, Paavonen T, Halttunen J, Häyry P (1991) Chronic rejection of rat aortic allograft. II. Administration of cyclosporin induces accelerated allograft arteriosclerosis. Transpl Int 4: 173-179.

107. Vuiblet V, Birembaut P, François A, Cordonnier C, Noel LH, et al. (2012) Sirolimus-based regimen is associated with decreased expression of glomerular vascular endothelial growth factor. Nephrol Dial Transplant 27: 411-416.

108. Parlar A, Can C, Erol A, Ulker S (2010) Posttransplantation therapeutic rapamycin concentration protects nitric oxide-related vascular endothelial function: comparative effects in rat thoracic aorta and coronary endothelial cell culture. Transplant Proc 42: 1923-1930.

109. Lemesle G, Schurtz G, Delhaye C (2013) Biolimus-eluting stent with biodegradable polymer (Noboriß): an overview of recent clinical results, SORT OUT V and COMPARE II trials. Expert Rev Cardiovasc Ther 11: 1293-1296.

110. Püschel A, Lindenblatt N, Katzfuss J, Vollmar B, Klar E (2012) Immunosuppressants accelerate microvascular thrombus formation in vivo: role of endothelial cell activation. Surgery 151: 26-36.

111. Laster ML, Fine RN (2014) Growth following solid organ transplantation in childhood. Pediatr Transplant 18: 134-141.

112. Höcker B, Weber LT, Feneberg R, Drube J, John U, et al. (2010) Improved growth and cardiovascular risk after late steroid withdrawal: 2-year results of a prospective, randomised trial in paediatric renal transplantation. Nephrol Dial Transplant 25: 617-624.

113. Nucci AM, Barksdale EM Jr, Beserock N, Yaworski JA, lurlano K, et al. (2002) Long-term nutritional outcome after pediatric intestinal transplantation. $J$ Pediatr Surg 37: 460-463. 
114. Evenepoel P (2013) Recovery versus persistence of disordered mineral metabolism in kidney transplant recipients. Semin Nephrol 33: 191-203.

115. Pichette V, Bonnardeaux A, Prudhomme L, Gagné M, Cardinal J, et al. (1996) Long-term bone loss in kidney transplant recipients: a cross-sectional and longitudinal study. Am J Kidney Dis 28: 105-114.

116. Boini KM, Nammi S, Grahammer F, Osswald H, Kuhl D, et al. (2008) Role of serum- and glucocorticoid-inducible kinase SGK in glucocorticoid regulation of renal electrolyte excretion and blood pressure. Kidney Blood Press Res 31: $280-289$.

117. Bhandaru M, Kempe DS, Rotte A, Capuano P, Pathare G, et al. (2011) Decreased bone density and increased phosphaturia in gene-targeted mice lacking functional serum- and glucocorticoid-inducible kinase 3. Kidney Int 80: 61-67.

118. Joseph C, Gattineni J, Dwarakanath V, Baum M (2013) Glucocorticoids Reduce Renal NHE8 Expression. Physiol Rep 1: e00031.
119. Jehle AW, Forgo J, Biber J, Lederer E, Krapf R, et al. (1997) Acid-induced stimulation of $\mathrm{Na}-\mathrm{Pi}$ cotransport in OK cells: molecular characterization and effect of dexamethasone. Am J Physiol 273: F396-403.

120. Hofbauer LC, Gori F, Riggs BL, Lacey DL, Dunstan CR, et al. (1999) Stimulation of osteoprotegerin ligand and inhibition of osteoprotegerin production by glucocorticoids in human osteoblastic lineage cells: potential paracrine mechanisms of glucocorticoid-induced osteoporosis. Endocrinology 140: 4382-4389.

121. Weisinger JR, Carlini RG, Rojas E, Bellorin-Font E (2006) Bone disease after renal transplantation. Clin J Am Soc Nephrol 1: 1300-1313.

122. Ing SW, Sinnott LT, Donepudi S, Davies EA, Pelletier RP, et al. (2011) Change in bone mineral density at one year following glucocorticoid withdrawal in kidney transplant recipients. Clin Transplant 25: E113-123.

123. Pennisi P, Trombetti A, Giostra E, Mentha G, Rizzoli R, et al. (2007) Pamidronate and osteoporosis prevention in liver transplant recipients. Rheumatol Int 27: 251-256. 